\title{
CASEREPORT
}

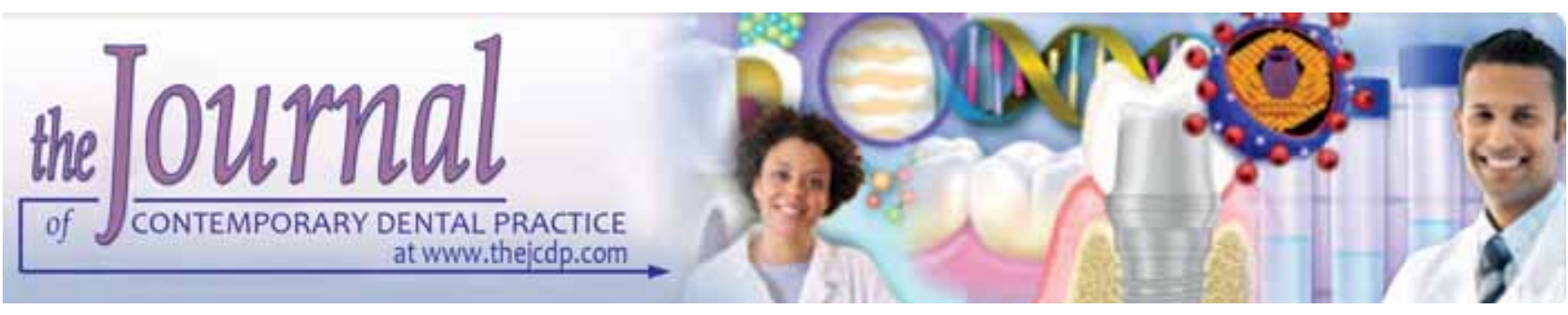

\section{Management of Maxillary Avulsed Teeth: Using Lasers for Canal Sterilization}

Indra Gupta, Satyendra Gupta, Kishore Sonwane, Dilip Damankar

\begin{abstract}
Background: Avulsion or exarticulation accounts for up to $16 \%$ of all traumatic injuries. It is most common in age group of 7 to 14 years. Following the loss of anterior teeth, the replacement is necessary to maintain esthetics, phonetics and avoid arch length discrepancy. Following replantation, postoperative care and management is done in several ways.
\end{abstract}

Case report: This article reports replantation and use of laser for endodontic sterilization and healing in a 12-year-old boy.

Conclusion: It is suggested that replantation of an avulsed tooth as soon as possible using appropriate splint and regular followup will show good prognosis.

Clinical significance: Laser offers itself as a good alternative to $\mathrm{Ca}(\mathrm{OH})_{2}$ for root canal sterilization and improved periapical healing.

Keywords: Avulsion, Replantation, Laser sterilization.

How to cite this article: Gupta I, Gupta S, Sonwane K, Damankar D. Management of Maxillary Avulsed Teeth: Using Lasers for Canal Sterilization. J Contemp Dent Pract 2011;12(4):322-326.

\section{Source of support: Nil}

Conflict of interest: None declared

\section{INTRODUCTION}

Avulsion or exarticulation is defined as a condition when a whole tooth is removed from the alveolar socket as a result of trauma. It is classified as class $\mathrm{V}$ injury under classification of traumatic injuries by Anderson. It accounts for $16 \%$ of all injuries in permanent dentition and $7.2 \%$ of injuries in primary dentition. ${ }^{1}$

Road accidents, sports injury, fall are a few reasons for avulsion; most common in age group of 7 to 12 years.

Management of avulsion is replantation which restores occlusal function and esthetics. The percentage of success of tooth replantation has been observed to be around 4 to $50 \%{ }^{2}$

The success of tooth reimplantation depends on maintenance of vitality of periodontal ligament adhered to avulsed tooth to survive and recover. ${ }^{3}$
Resorption is the main cause of failure of reimplantation and the prognosis depends on type of resorption. ${ }^{4}$

Endodontic treatment is necessary since, the pulp tissue may show necrosis or may show periapical infection due to toxins which may get lodged during replantation procedure. ${ }^{5}$

Sterilization of canals is important under endodontic treatment and for faster healing, biostimulation can be done with lasers. ${ }^{6}$

\section{CASE REPORT}

A 12-year-old-boy reported to dental clinic because of fall from stairs. The extraoral examination revealed swelling of upper lip and laceration (Fig. 1).

Intraoral examination revealed: Loss of right and left central and lateral incisors (Fig. 1).

- The radiovisiography showed the loss of all four anteriors with a normal socket and no evidence of bone or tooth fracture (Figs 2 and 3)

- The avulsed teeth were brought by the patient in his hand within 20 minutes of the trauma. The teeth appeared normal with no signs of breakage. Patient had no relevant medical history. The periodontal ligament was not dried

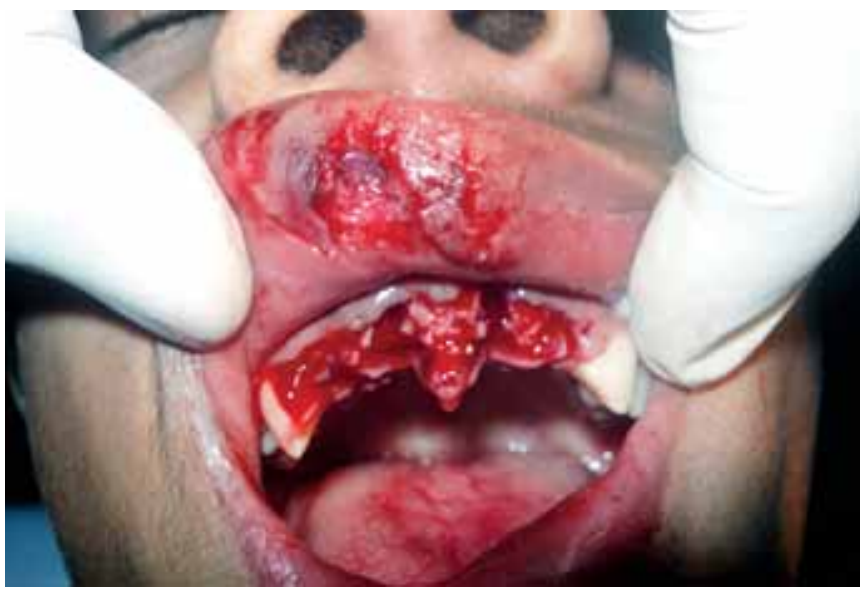

Fig. 1: Preoperative photograph showing injured upper lip and loss of anterior teeth 


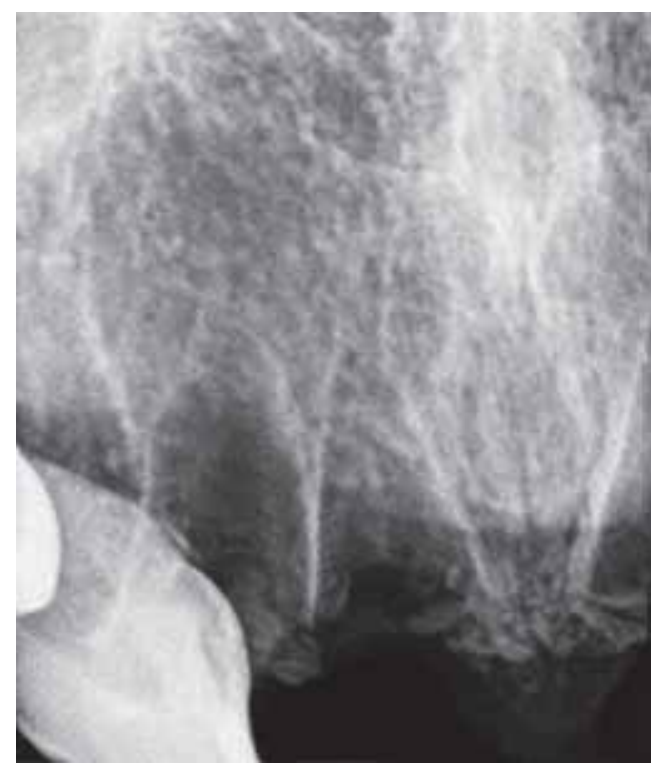

Fig. 2: Socket 11 and 12

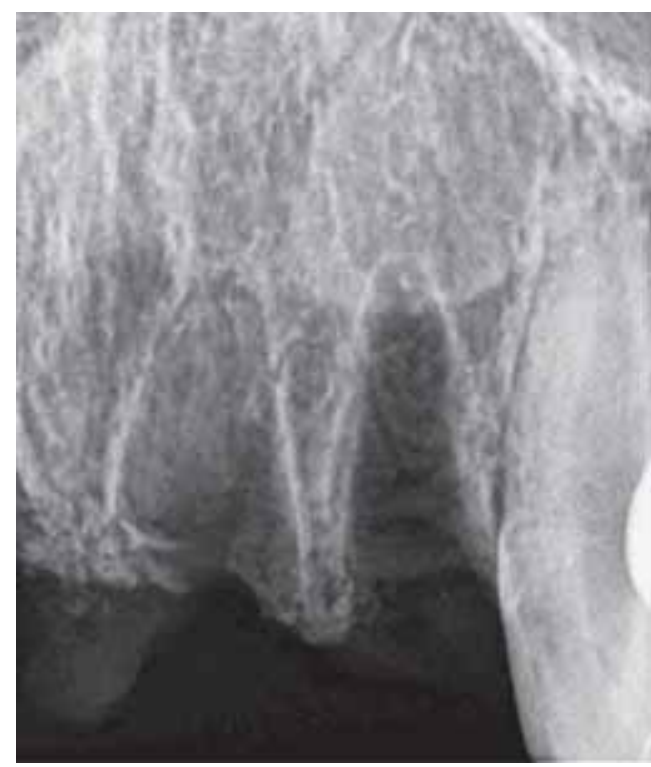

Fig. 3: Soket 21 and 22

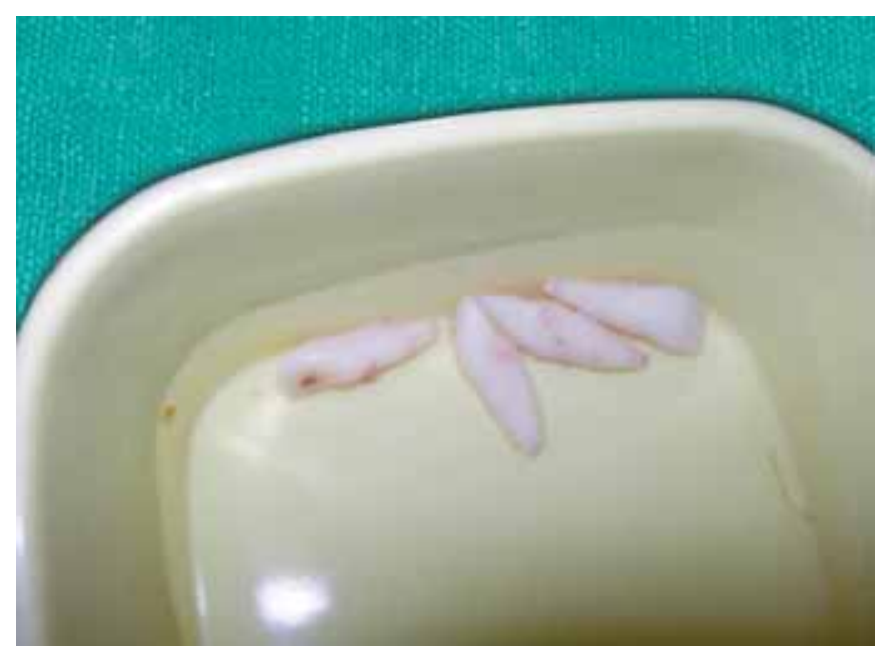

Fig. 4: Avulsed teeth
- The teeth were placed in normal saline $(0.7 \%)$ when the patient arrived at the clinic (Fig. 4)

- Local anesthetic was administered, the area was cleaned with povidone iodine, and the teeth were then reimplanted into their sockets with the help of finger pressure followed by radiographs to ensure their correct placement into the socket (Fig. 5)

- The teeth were then splinted with Targis-Vectris, which is a fiber reinforced composite for a week (Figs 6 to 8)

- Patient was prescribed systemic antibiotics and analgesics, antitetanus serum was given after asking his parents. Also instruction for maintenance of oral hygiene and quitting of acidic beverages and soft diet was advised.

- Patient was recalled after a week when a draining sinus was seen in relation to 11 and 12 (Figs 9 and 10).

Thereby, endodontic treatment was planned for all four anteriors. After access opening, dressing was given and temporary restoration done.

- After a week splints were removed. Theoretically, $\mathrm{Ca}(\mathrm{OH})_{2}$ dressing is to be placed after 2 to 3 weeks of

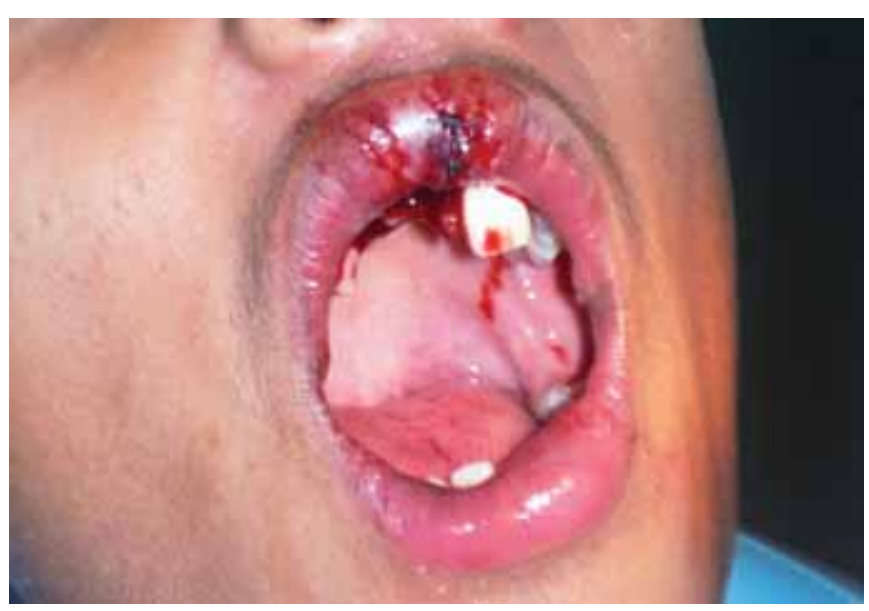

Fig. 5: Replanted 21

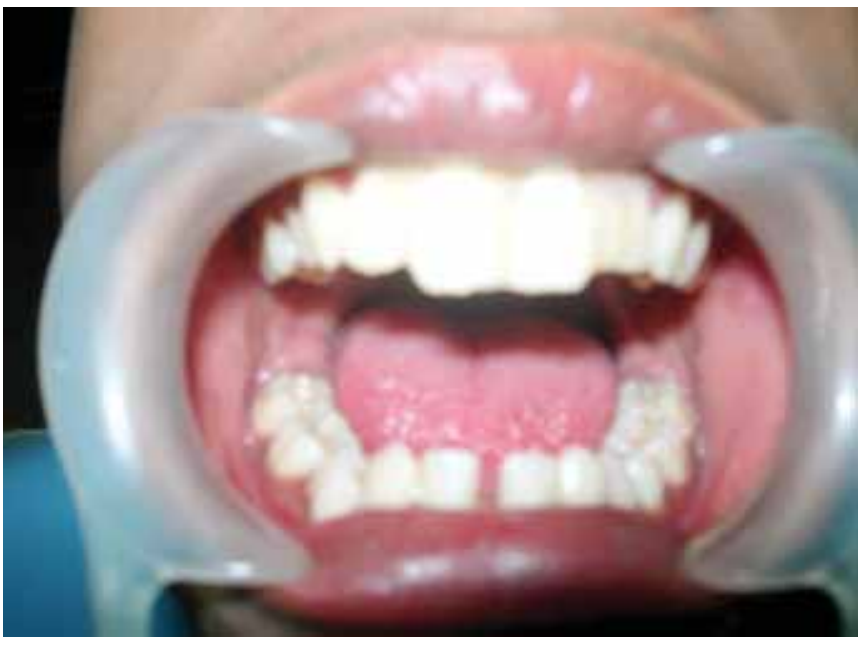

Fig. 6: After splinting 


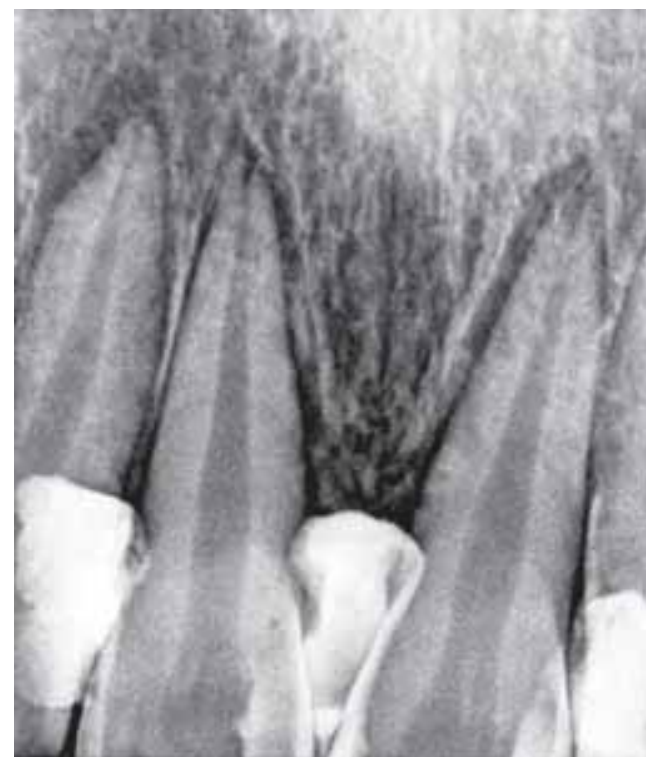

Fig. 7: Immediately after replantation and splinting 11 and 12

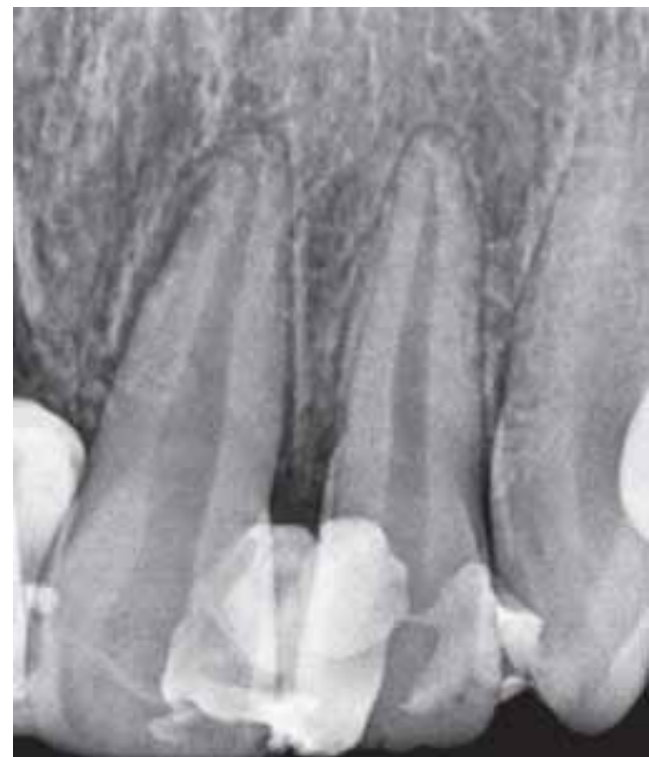

Fig. 8: Immediately after replantation and splinting 21 and 22

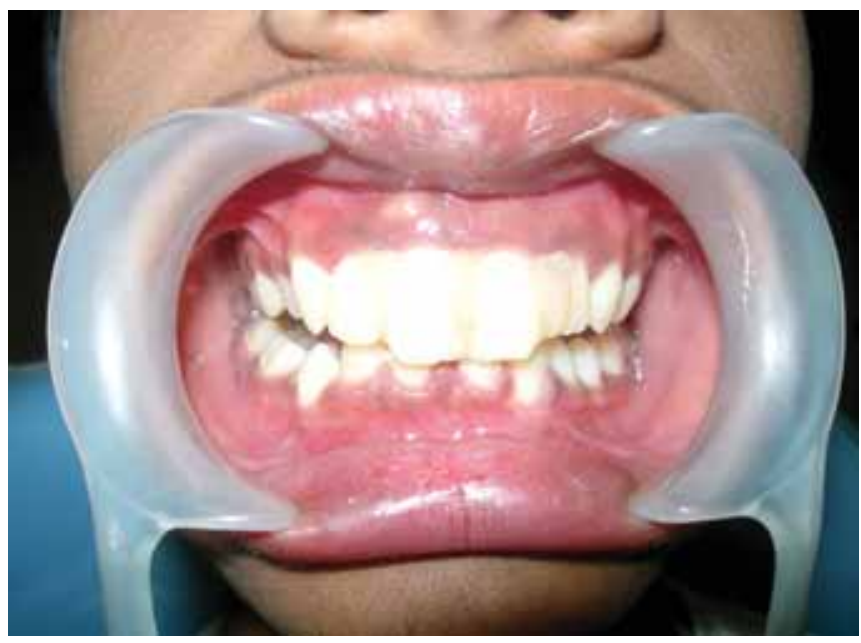

Fig. 9: Draining sinus irt 11

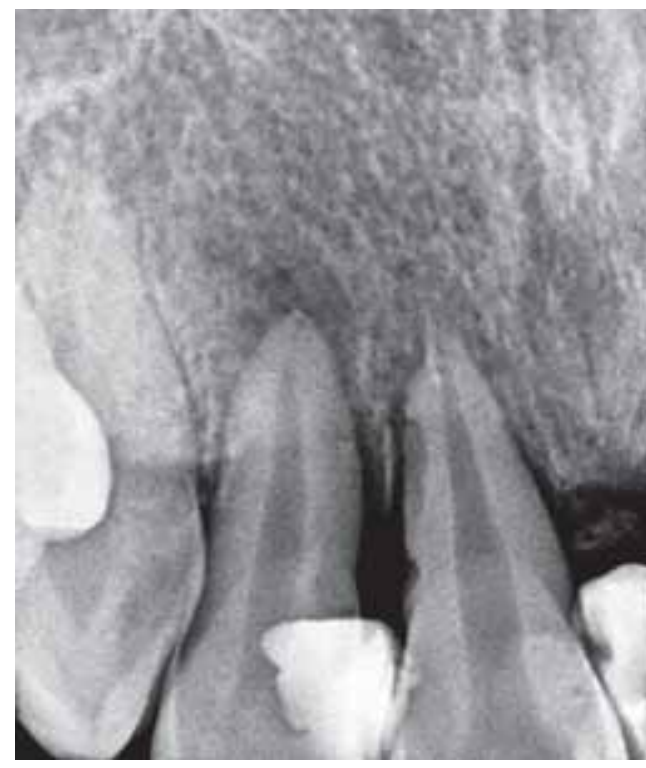

Fig. 10: After 2 weeks

replantation (to reduce external resorption) but we decided to give a laser shot instead at this juncture to fasten the healing process. Specification-150 mJ, $15 \mathrm{~Hz}$, 5 sec.

- Next week clinically mobility was reduced and the draining sinus healed graft (Figs 11 and 12).

- Follow-up radiographs were taken every month (Fig. 13)

- There was no evidence of root resorption, and the teeth were stable in the socket with no signs of mobility (Figs 14 and 15)

- Finally the obturation was done after 3 weeks and radiographs were taken (Figs 16 and 17).

\section{DISCUSSION}

The success of avulsed teeth depends entirely in extraoral dry time or time elaspsed between injury and replantation and storage media of teeth. Teeth that have been replanted within 30 minutes of loss have an excellent prognosis. ${ }^{6,7}$

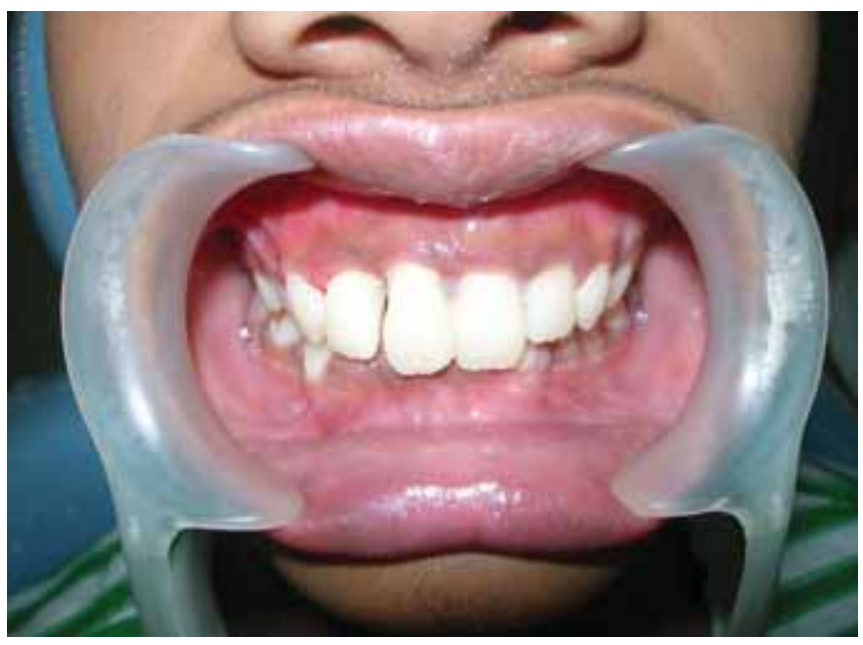

Fig. 11: Draining sinus subsided after endodontic and laser irradiation 


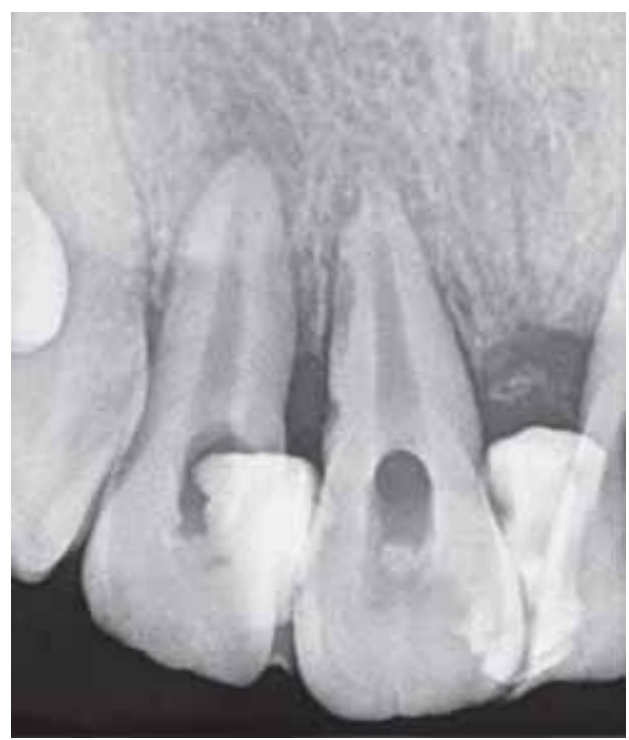

Fig. 12: After the laser shot

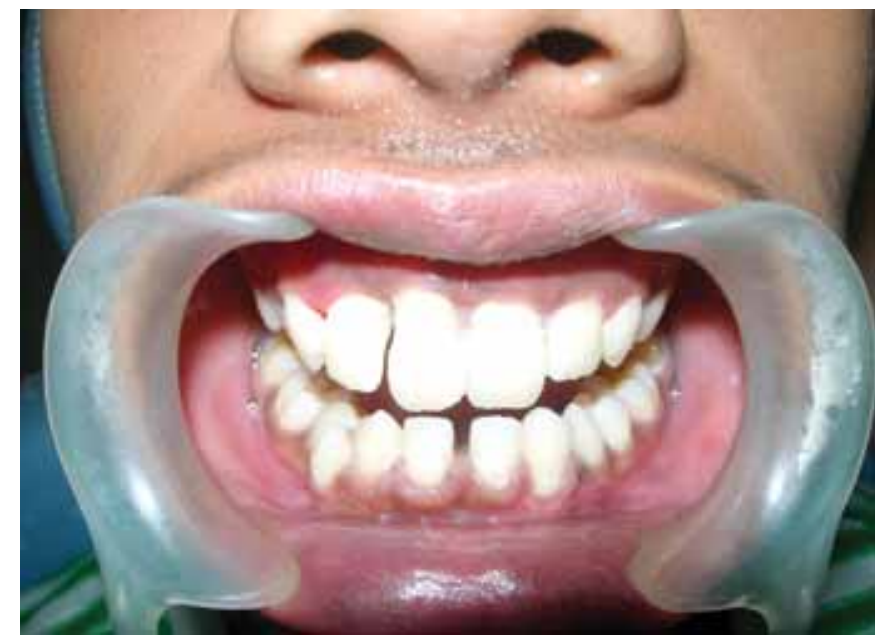

Fig. 13: After 2 months

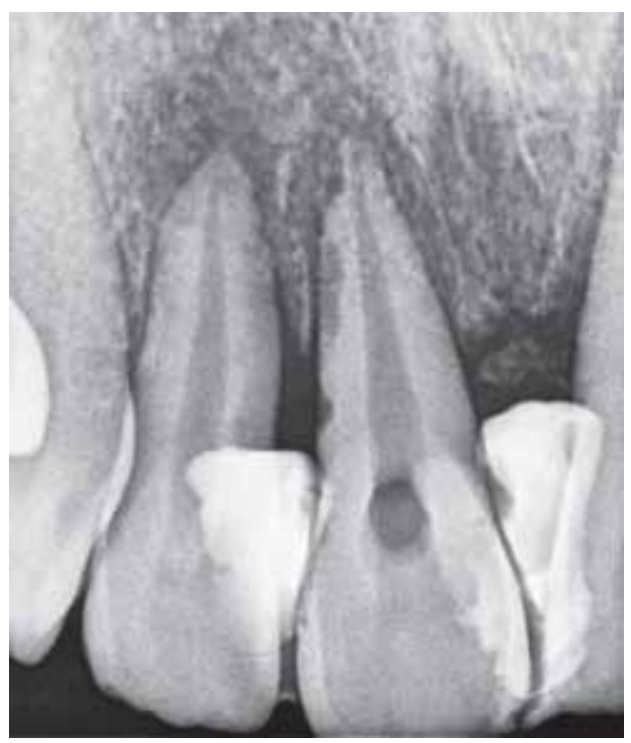

Fig. 14: Preobturation 11 and 12

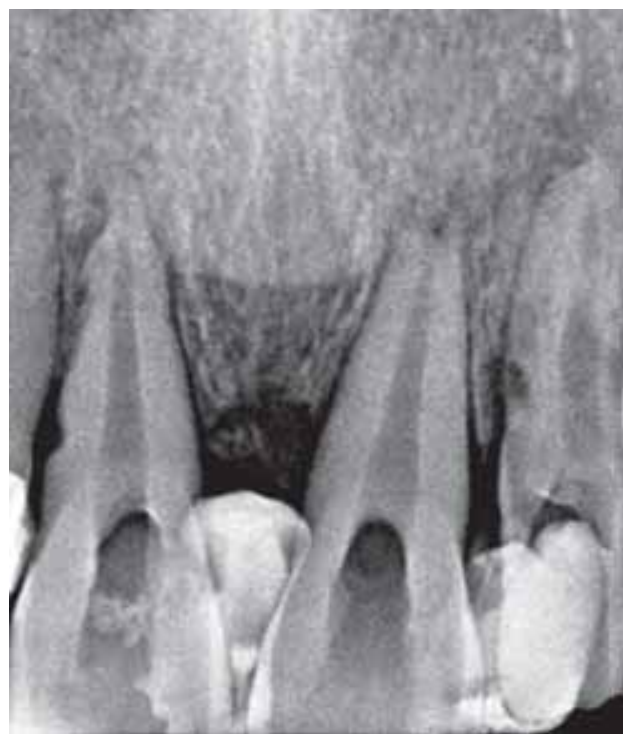

Fig. 15: Preobturation 21 and 22

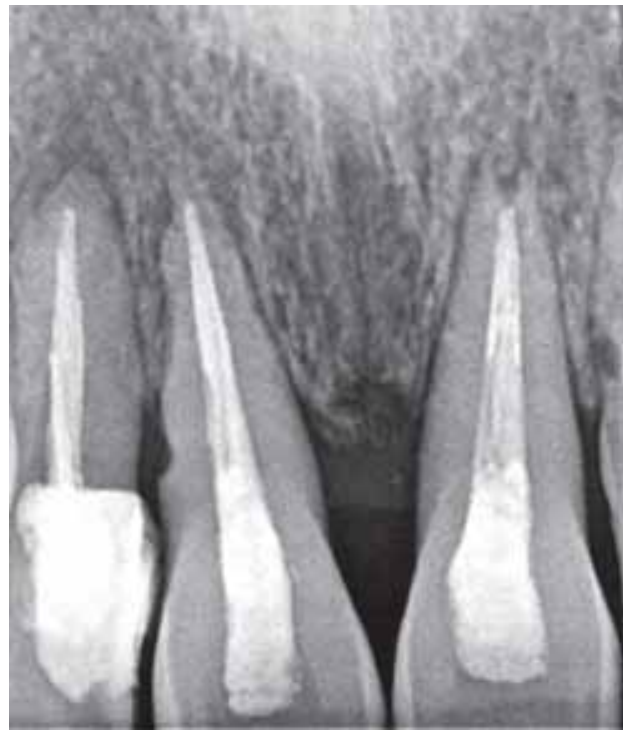

Fig. 16: Postobturation 11 and 12 after 5 weeks

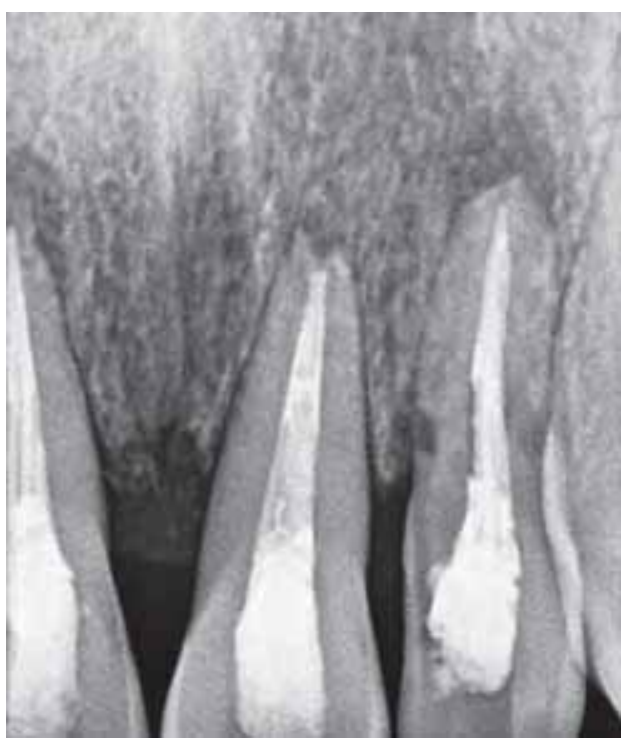

Fig. 17: Postobturation 21 and 22 after 5 weeks 
The choice of storage media for preserving traumatic avulsed teeth is important for success of replantation. Ideally, the best known solution is Hank's balanced salt solution. ${ }^{8,9}$

Other storage media include milk, saliva, physiological saline, buccal vestibule.,

In our case, we splinted the teeth with targis vectris technique. During this period, the patient was recommended to avoid biting on splinted teeth and maintain oral hygiene. Splints were removed after a week to prevent ankylosis. ${ }^{11}$

Lasers were used which increase vascularization, activate cytokines, growth factors, necessary fibroblasts and chondrocytes and osteoblast proliferation that activates bond regeneration. Biomodulation of nondifferentiated mesenchymal cells to obteoblast occurs which increases healing. Collagen synthesis also increases by low level laser therapy. ${ }^{11-13}$

Additional systemic antibiotics and analgesics were prescribed.

\section{CONCLUSION}

Our study suggests that replantation of an avulsed tooth as soon as possible and using appropriate splint and use of lasers in place of $\mathrm{Ca}(\mathrm{OH})_{2}$ for a faster periapical healing and regular follow-up after treatment by a dentist will show good prognosis.

\section{ACKNOWLEDGMENT}

Dr Seema Sadhwani and the staff are acknowledged for their support and help.

\section{REFERENCES}

1. Katalin Gabris, Ildiko Tarjam. Dental trauma in children presenting for treatment in department of pediatric dentistry and orthodontics. Dental Traumatology 2001;15:103-08.

2. Andreason JO, Borum MK, Jacobsen HL, Andreason FM. Replantation of 400 avulsed permanent incisors. Four factors related to periodontal ligament healing. Endod Dent Traumatol 1995;11:76-89.
3. Andreason JO. A time related study on periodontal ligament healing and root resorption activity after replantation of mature permanent incisors in monkey. Swed dent J 1980;4:101-10.

4. Andreason JO. Effect of extra-alveolar period and storage media upon PDL and pulpal healing after replantation of mature permanent incisors in monkeys. Int J Orl Surg 1981;10:43-53.

5. Barrett EJ, Kemy DJ. Avulsed permanent teeth: A review of literature and treatment guidelines. Endod Dent Traumatol 1997; 13:153-63.

6. Andreason JO, Hioting-Hansen E. Replantation of teeth: Radiographic and clinical study of 110 human teeth replanted after accidental loss. Acta Odontol Scana 1966;24:263-86.

7. Anderson L, Bondin L. Avulsed human teeth replanted within 15 mins - a long-term clinical follow-up study. Endod Dent Traumatol 1990;6:37-42.

8. Blom L of L. Milk and saliva as possible storage media for traumatically exarticulated teeth prior to replantation. Swed Dent J (Suppl)1981:8-25.

9. Trope M, Freidman S. Periodontal healing of replanted dogs teeth stored in via span milk, Hanks balanced salt solution. Endodent Traumatol 1992;8:183-88.

10. Heimamm GR, Biven GM, Kahn H, Smmulson M. Temporary splinting using adhesive system. Oral Surg 1971;31:652.

11. Hommura A, et al. Therapeutic effects of goal as diode laser irradication on experimentally induced inflammation in rats. Laser in Surgery and Medicine 1992;12:441-49.

12. JBB Weber, Pinheiro AL, de Oliveira MG, Ramalhol M. Laser therapy healing of bone defects submitted to autologous bone graft. Photomed laser surg 2006;24(1):38-44.

13. Giuliani A, et al. Int. J Tissue React 2004;26(1-2):29-37.

\section{ABOUT THE AUTHORS}

\section{Indra Gupta (Corresponding Author)}

Professor and Head, Department of Conservative Dentistry and Endodontics, Rishi Raj Dental College, Bhopal, Madhya Pradesh India, e-mail: drindra29068@rediffmail.com

\section{Satyendra Gupta}

Senior Lecturer, Department of Oral and Maxillofacial Surgery Rishi Raj Dental College, Bhopal, Madhya Pradesh, India

\section{Kishore Sonwane}

Professor and Head, Department of Oral and Maxillofacial Pathology Rishi Raj Dental College, Bhopal, Madhya Pradesh, India

\section{Dilip Damankar}

Principal, Rishi Raj Dental College, Bhopal, Madhya Pradesh, India 